\title{
EFFECT OF LATTICE STRUCTURES TOPOLOGY ON THE PROPERTIES OF THE TINi ALLOY: COMPUTER SIMULATION
}

\author{
Eduard FARBER, Alexey ORLOV, Anatoly POPOVICH \\ Peter the Great St. Petersburg Polytechnic University, St. Petersburg, Russian Federation, \\ d.farber2010@yandex.ru
}

https://doi.org/10.37904/metal.2021.4242

\begin{abstract}
TiNi alloy, also known under the commercial name Nitinol, is one of the best known shape memory alloys. Currently, there are many studies related to the possibility of obtaining this alloy using additive manufacturing technologies, especially selective laser melting. Some of these studies are devoted to the issue of obtaining lattice structures with different topology from TiNi alloy. Such structures could potentially find application in the medical field, as implants for various purposes. TiNi alloy has a sufficiently low modulus of elasticity, close to the elasticity modulus of a bone structures. In these works, it is assumed that the topology and porosity of the lattice structure of the TiNi alloy, produced by the selective laser melting method, influences the mechanical properties of the alloy. For a more complete analysis of this phenomenon, the presented research work was carried out. In this work, computer modelling of unit cells and full-fledged TiNi alloy lattice structures was carried out. Several strut based unit cell topologies were selected and modelled. Further, a volumetric lattice structure on the basis of the unit cell topologies was modelled and its mechanical properties were calculated. The modelling process is implemented with ANSYS 2019 R2 SpaceClaim finite element analysis package. The results of the work confirmed the presence of the influence of the unit cell topology on the mechanical properties of the TiNi alloy.
\end{abstract}

Keywords: TiNi, nitinol, computer simulation, lattice structure, mechanical properties

\section{INTRODUCTION}

Nitinol, an equiatomic alloy of titanium and nickel, is one of several known alloys that are capable to exhibit shape memory effect. The alloy was patented in 1965 and was first used in the late 60s in aviation as a coupling for a hydraulic system pipeline [1]. Later, Nitinol began to be used in other areas of science and technology, in the role of temperature sensors, actuators, thermomechanical connecting elements, etc. [2]. The alloy is also used in the medical field: in orthopedics as medical tightening braces and other implants for the treatment of various diseases of the bone system, in dentistry as braces, in cardiology as stents and in other areas [1-3].

The prospects for further expanding the applicability of Nitinol are inextricably linked with the development of modern technologies, in particular, with the additive manufacturing technologies. To date, there are many scientific works devoted to the production of products from the Nitinol (TiNi) alloy using additive manufacturing technologies and the influence of the process and processing parameters on the final properties of the alloys $[4,5]$. As a method of obtaining dense products from TiNi alloy, the selective laser melting method is most often considered [6,7].

In addition to obtaining dense structures from TiNi alloys by the SLM method, it is also possible to obtain structures with a complex geometry - lattice structure. At the moment, there are several works devoted to the simulation and growth of such structures using the selective laser melting method, and the study of their properties [8-14]. These structures are promising for use in medicine as implants for various purposes. Nitinol 
has a sufficiently low modulus of elasticity - about $48 \mathrm{GPa}$. This is close enough to the value of the elastic modulus of the human cortical bone -12-17 GPa [14], but still higher than the value of the elastic modulus of the cancellous bone: $0.1-5 \mathrm{GPa}[15,16]$. It is known that implants made of materials with high stiffness bear a significant part of the body load. Accordingly, the surrounding bone will experience less stress, which can lead to bone resorption at the interface between the implant and the bone and to gradual detachment of the implant [14]. The use of a porous (lattice) structure of an implant made of TiNi alloy will reduce the modulus of elasticity and bring it closer to the value of the bone modulus, which will reduce the risk of development of stress shielding effect $[9,14]$. In existing studies, it is noted that the modulus of elasticity decreases with an increase in the porosity of the lattice structure. The existence of a relationship between the topology of a unit cell of the lattice structure and the exhibited properties of the alloy is also indicated [9]. However, a full-fledged study of this relationship has not been conducted. At the same time, in [10] it was noted that modelling can be implemented to predict the behavior of TiNi parts with different levels of porosity and topology.

This paper presents the results of the first stage of the study of the effect of the topology of the lattice structure on the properties of the TiNi alloy. To implement the first stage of the study, a computer numerical simulation of strut based lattice structures with six different topologies of unit cells with different porosities was carried out. SC, BCC, and BCC-Z unit cells, previously presented in $[9,10]$ and an S-FBCC unit cell [17], which was not previously presented in studies of TiNi lattice structures, were selected as topologies. Also, on the basis of works [18,19], devoted to implants made of Ti6Al4V alloy, two topologies of unit cells with negative Poisson's ratio were developed. Simulation of such unit cells from a TiNi alloy is carried out for the first time. Negative Poisson's ratio in implants will solve the problem of "detachment", described in [19]. Further, the following characteristics were calculated - elastic modulus, modulus of elasticity in shear, Poisson's ratio. On the basis of the calculated data, graphs of dependences of elastic characteristics on the topology of a unit cell were obtained. The obtained data confirm and more fully characterize the dependence of the properties of the alloy on the topology of the lattice structure. The results will be verified experimentally at the next stage of research. In the future, the research results will make it possible to develop a full-fledged technology for producing lattice implants with programmable properties from TiNi shape memory alloys grown by selective laser melting.

\section{METHODS}

a)
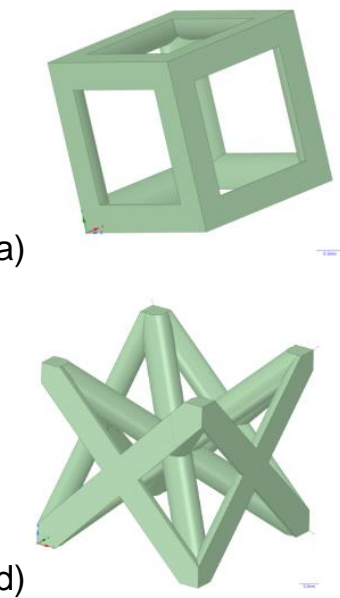

b)

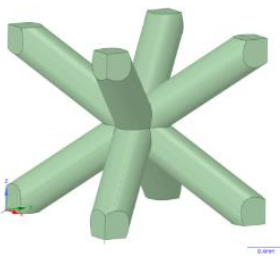

e)

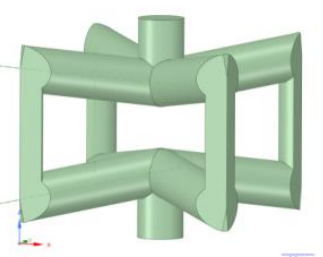

c)

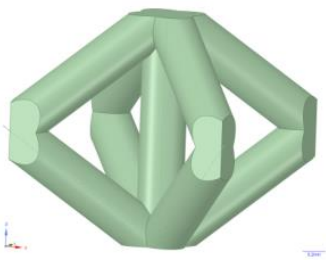

f)

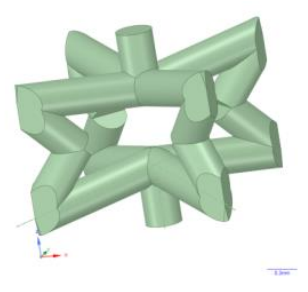

Figure 1 Unit cell topologies: a - Type 1, b-Type 2, c - Type 3, d-Type 4, e - Type 5, f - Type 6

For the study, 6 types of strut-based unit cell topologies were selected: Type 1 - SC, Type $2-$ BCC, Type $3-$ BCC-Z, Type 4 - S-FBCC, Type 5 and Type 6 - with negative Poisson's ratio. Unit cell topologies were built using ANSYS 2019 R2 Space Claim. Size of each cell is $2 \times 2 \times 2 \mathrm{~mm}$. The porosity of each cell was varied $80 \%, 70 \%$ and $60 \%$. The porosity was varied by thickening the cell struts. Examples of unit cell geometries 
with $80 \%$ porosity are shown in Figure 1. Lattice structures on the basis of each topology of a unit cell consisting of 5 cells along three axes $(5 \times 5 \times 5)$ with corresponding porosities were generated. An example of a lattice structure with Type 4 unit cell topology is shown in Figure 2. The mechanical characteristics for the constructed lattice structures were further determined: Young's modulus $(E)$, modulus of elasticity in shear $(G)$, and Poisson's ratio $\mu$. The determination was carried out using the numerical simulation of the compression experiment of the constructed lattice structures. The initial modeling data were based on the TiNi alloy with equiatomic composition: Young's modulus of austenite $-77 \mathrm{GPa}$, Young's modulus of martensite $-30 \mathrm{GPa}$, Poisson's ratio -0.33 , modulus of elasticity in shear $-29 \mathrm{GPa}$, density $-6500 \mathrm{~kg} / \mathrm{m}^{3}$.

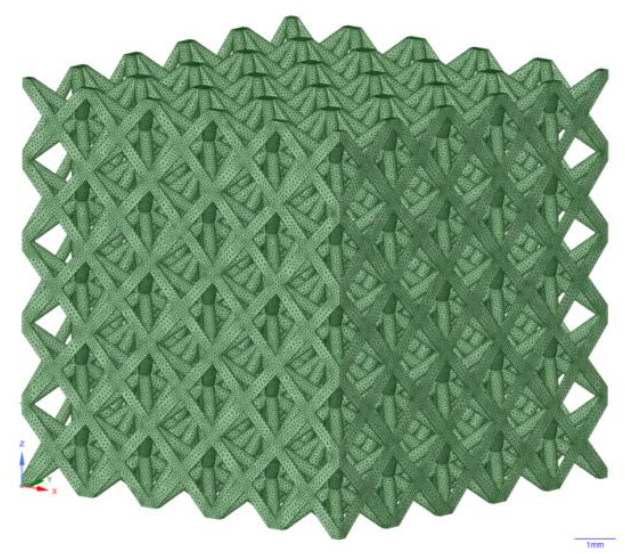

Figure 2 Lattice structure with Type 4 unit cell topology

\section{RESULTS}

The mechanical characteristics of lattice structures with different topology of unit cells, obtained in the results of numerical computer simulation, are presented in Table 1, where is the porosity of the structure $(80 \%, 70 \%$, $60 \%), E$ is Young's modulus, $G$ is the modulus of elasticity in shear, $\mu$ is Poisson's ratio, $T$ is the thickness of the struts of the structure. For clarity of the obtained results, graphs of the dependence of Young's modulus, modulus of elasticity in shear and Poisson's ratio on the type of unit cell topology with division by the level of porosity were plotted based on the data from Table 1. Dependency graphs are shown in Figures 3, 4, 5, respectively.

Table 1 Results of numerical computer modelling of lattice structures - mechanical characteristics

\begin{tabular}{|l|c|c|c|c|c|c|}
\hline & Type 1 & Type 2 & Type 3 & Type 4 & Type 5 & Type 6 \\
\hline E P08 $(\mathrm{GPa})$ & 7.06 & 0.78 & 3.61 & 1.31 & 0.61 & 0.61 \\
\hline $\boldsymbol{E}$ P07 $(\mathrm{GPa})$ & 11.64 & 2.31 & 6.89 & 3.20 & 1.48 & 1.78 \\
\hline $\boldsymbol{E}$ P06 $(\mathrm{GPa})$ & 17.05 & 5.27 & 11.58 & 6.40 & 2.76 & 3.65 \\
\hline G P08 $(\mathrm{GPa})$ & 0.42 & 2.37 & 2.17 & 1.51 & 3.68 & 3.06 \\
\hline G P07 $(\mathrm{GPa})$ & 1.18 & 3.94 & 3.69 & 2.72 & 5.85 & 5.14 \\
\hline G P06 $(\mathrm{GPa})$ & 2.55 & 5.81 & 5.57 & 4.40 & 8.22 & 7.68 \\
\hline $\boldsymbol{\mu}$ P08 & 0.09 & 0.45 & 0.09 & 0.68 & -0.13 & -0.07 \\
\hline $\boldsymbol{\mu}$ P07 & 0.12 & 0.42 & 0.12 & 0.57 & -0.08 & -0.02 \\
\hline $\boldsymbol{\mu}$ P06 & 0.15 & 0.39 & 0.15 & 0.48 & -0.03 & 0.05 \\
\hline $\boldsymbol{T}$ P08 $(\mu \mathrm{m})$ & 640 & 430 & 400 & 320 & 420 & 370 \\
\hline $\boldsymbol{T}$ P07 $(\mu \mathrm{m})$ & 820 & 540 & 510 & 410 & 530 & 470 \\
\hline $\boldsymbol{T}$ P06 $(\mu \mathrm{m})$ & 980 & 640 & 600 & 490 & 630 & 570 \\
\hline
\end{tabular}




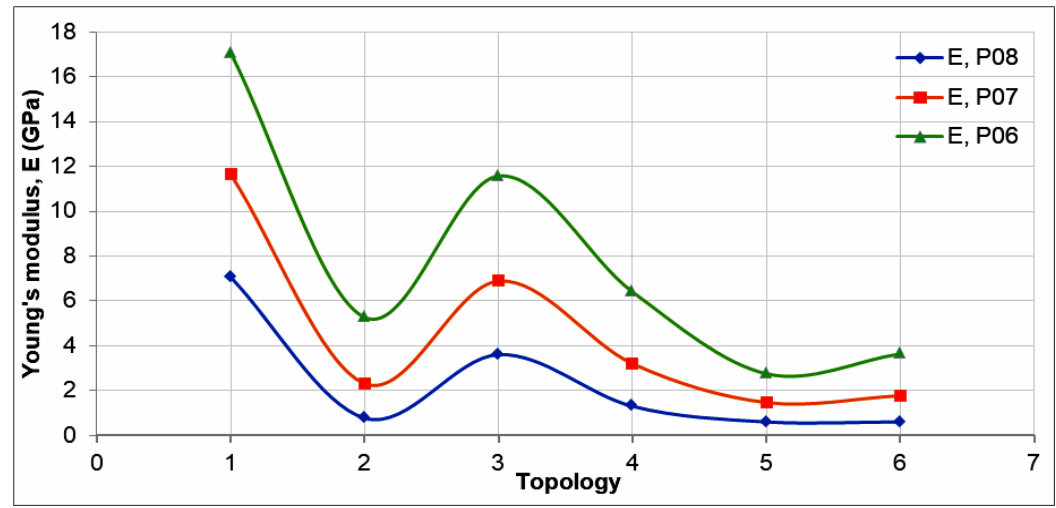

Figure 3 Graph of the dependence of the Young's modulus of the lattice structure on the topology of a unit cell

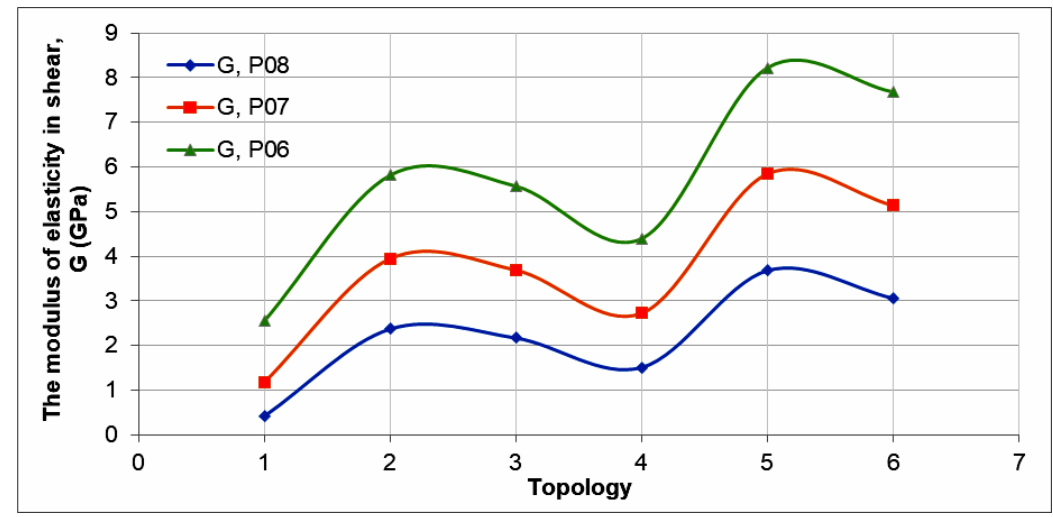

Figure 4 Graph of the dependence of the modulus of elasticity in shear of the lattice structure on the topology of a unit cell

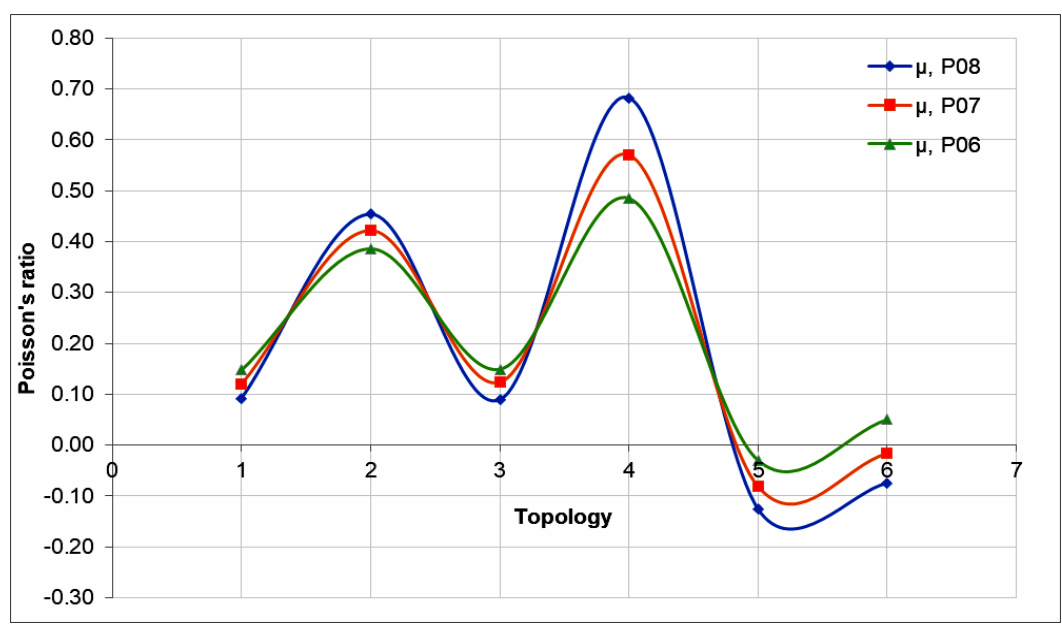

Figure 5 Graph of the dependence of the Poisson's ratio of the lattice structure on the topology of a unit cell

As can be seen from the graph presented in Figure 3, the Young's modulus is directly dependent on the applied topology of the unit cell. The highest value of the Young's modulus for all porosity options is achieved for the Type 1 topology $17 \mathrm{GPa}$. With a porosity of $70 \%$, the Young's modulus was $11.6 \mathrm{GPa}$. Accordingly, when using the Type 1 topology with porosity from 60 to $70 \%$, the Young's modulus of the lattice structure will 
be in the range of the Young's modulus of the human cortical bone. The lowest level of Young's modulus was shown by the Type 5 topology: at $80 \%$ porosity, Young's modulus was $0.6 \mathrm{GPa}$, and at $60 \%-2.8 \mathrm{GPa}$. Such indicators are within the elastic modulus of the cancellous bone. Structures with topologies Type 2, Type 4, and Type 6 also have rather low Young's modulus, close to the Young's modulus of cancellous bone. The structure with the Type 3 topology took an intermediate position - with a porosity of $80 \%$, the Young's modulus was $3.6 \mathrm{GPa}$. A further decrease in porosity led to an increase in Young's modulus to a level of $11.6 \mathrm{GPa}$, which is higher than Young's modulus of cancellous bone, but lower than Young's modulus of cortical bone.

The opposite situation is observed in Figure 4. The lowest modulus of elasticity in shear level was shown by the Type 1 topology, while the Type 5 and Type 6 topologies showed the highest modulus of elasticity in shear level among the available topologies. Figure 4 also clearly shows the presence of a relationship between the topology of a unit cell and the final properties of the structure.

Figure 5 shows that the Type 5 and Type 6 topologies have negative Poisson's ratio, as expected in the design of the unit cell. Accordingly, using the topology data, it is possible to obtain a lattice structure of auxetic materials from the TiNi alloy. At the same time, it can be observed that a decrease in porosity leads to a gradual increase in Poisson's ratio. The Type 6 lattice structure with 60\% porosity already has the positive Poisson's ratio like in conventional materials. Note also that Type 2 and Type 4 topologies have very high Poisson's ratio, which characterizes these lattice structures as an elastic incompressible material.

The data obtained are generally consistent with the scientific works of other authors. In [9] structures with a unit cell topology similar to Type 1 (SC) were previously grown from TiNi powder with an almost equiatomic composition by the SLM method. The cell dimension was similar to the cell dimensions in this work. With a porosity of $58 \%$ and a strut thickness of $1000 \mu \mathrm{m}$, the resulting lattice structure had an elastic modulus of 20.5 GPa. Similar results are presented in [8]. This practical value is quite close to the value of the elastic modulus obtained by computer simulation in our work for a structure with the Type 1 topology - $17.0 \mathrm{GPa}$ with a porosity of $60 \%$ and a strut thickness of $980 \mu \mathrm{m}$. In [9] a structure with a BCC-Z topology similar to the Type 3 topology was grown. Structure unit cell size $2.33 \times 2.33 \times 2.33 \mathrm{~mm}$, strut thickness $-650 \mu \mathrm{m}$, porosity $65 \%$. Young's modulus of the network structure obtained by the SLM method was $16.5 \mathrm{GPa}$. In our work, Young's modulus for a structure with a similar topology Type 3 and porosity of $60 \%$, obtained by computer simulation, was 11.58 $\mathrm{GPa}$. These are fairly close values. Some discrepancy, slightly more than that of the previously described structures with the Type 1 (SC) topology, can be explained by the difference in the sizes of the cells and struts. In our work, the cell size was $2 \times 2 \times 2 \mathrm{~mm}$ with a strut thickness of $600 \mu \mathrm{m}$, which is $50 \mu \mathrm{m}$ less than the strut thickness of the structure in [9]. Larger cell size and thicker struts made it possible to obtain a higher value of the modulus of elasticity with a larger value of porosity by $5 \%$. Generally, we can confidently state that the values of the modulus of elasticity obtained during computer modeling are in close agreement with the real characteristics of the lattice structures of the TiNi alloy obtained by the SLM method. Accordingly, the rest of the data obtained for structures with different unit cell topologies and different porosities are indicative.

\section{CONCLUSION}

The modelling carried out in the presented work confirmed the existence of a relationship between the topology of a unit cell of the lattice structure and the mechanical properties of this structure. Highly porous TiNi lattice structures with different unit cell topologies allow the Young's modulus to be reduced to the level of cortical or cancellous bone. The theoretical possibility of creating auxetic materials from TiNi alloy has been confirmed. The possibility of modelling the mechanical characteristics of lattice structures with different topology of a unit cell makes it possible to develop lattice structures with programmable properties, which can become the basis for the development of a full-fledged technology for manufacturing implants from TiNi alloys by selective laser melting. The obtained results of computer modelling will be verified at the next stage of research. 


\section{ACKNOWLEDGEMENTS}

\section{The reported study was funded by RFBR according to the research project № 20-38-90031.}

\section{REFERENCES}

[1] MANTOVANI, D. Shape memory alloys: Properties and biomedical applications. JOM. Oct. 2000, vol. 52, no. 10, pp. 36-44.

[2] OTSUKA, K., KAKESHITA, T. Science and technology of shape-memory alloys: New developments. MRS Bull. Feb. 2002, vol. 27, no. 2, pp. 91-100.

[3] MOHD JANI, J., LEARY, M., SUBIC, A., GIBSON, M.A. A review of shape memory alloy research, applications and opportunities. Mater. Des. Apr. 2014, vol. 56, pp. 1078-1113,

[4] ELAHINIA, M., SHAYESTEH MOGHADDAM, N., TAHERI ANDANI, M., AMERINATANZI, A., BIMBER, B.A., HAMILTON, R.F. Fabrication of NiTi through additive manufacturing: A review. Prog. Mater. Sci. Oct. 2016, vol. 83, pp. 630-663.

[5] ZHU, J. N., BORISOV, E., LIANG, X., FARBER, E., HERMANS, M.J.M., POPOVICH, V.A. Predictive analytical modelling and experimental validation of processing maps in additive manufacturing of nitinol alloys. Addit. Manuf. December 2020, vol. 38, p. 101802.

[6] SAEDI, S., SHAYESTEH MOGHADDAM, N., AMERINATANZI, A., ELAHINIA, M. KARACA, H.E. On the effects of selective laser melting process parameters on microstructure and thermomechanical response of Ni-rich NiTi. Acta Mater. Feb. 2018, vol. 144, pp. 552-560.

[7] MA, J. et al. Spatial control of functional response in 4D-printed active metallic structures. Sci. Rep. May 2017, vol. 7, no. 1, p. 46707.

[8] TAHERI ANDANI, M. et al. Achieving biocompatible stiffness in NiTi through additive manufacturing. J. Intell. Mater. Syst. Struct. Nov. 2016, vol. 27, no. 19, pp. 2661-2671.

[9] TAHERI ANDANI, M. et al. Mechanical and shape memory properties of porous Ni $50.1 \mathrm{Ti} 49.9$ alloys manufactured by selective laser melting. J. Mech. Behav. Biomed. Mater. Apr. 2017., vol. 68, pp. 224-231.

[10] SAEDI, S. et al. Shape memory response of porous NiTi shape memory alloys fabricated by selective laser melting. J. Mater. Sci. Mater. Med. Apr. 2018, vol. 29, no. 4, p. 40.

[11] SPEIRS, M., VAN HOOREWEDER, B., VAN HUMBEECK, J., KRUTH, J.P. Fatigue behaviour of NiTi shape memory alloy scaffolds produced by SLM, a unit cell design comparison. J. Mech. Behav. Biomed. Mater. 2017, vol. 70, no. October 2016, pp. 53-59.

[12] WALKER, J.M., HABERLAND, C. et al. Process development and characterization of additively manufactured nickel-titanium shape memory parts. J. Intell. Mater. Syst. Struct. Nov. 2016, vol. 27, no. 19, pp. 2653-2660.

[13] BORMANN, T., DE WILD, M., BECKMANN, F., MÜLLER, B. Assessing the morphology of selective laser melted NiTi-scaffolds for a three-dimensional quantification of the one-way shape memory effect. Behav. Mech. Multifunct. Mater. Compos. 2013, vol. 8689, p. 868914.

[14] RAHMANIAN, R., SHAYESTEH MOGHADDAM, N., HABERLAND, C., DEAN, D., MILLER, M., ELAHINIA, M. Load bearing and stiffness tailored NiTi implants produced by additive manufacturing: a simulation study. Behav. Mech. Multifunct. Mater. Compos. 2014, vol. 9058, p. 905814.

[15] DE WITTE, T.M., FRATILA-APACHITEI, L.E., ZADPOOR, A.A., PEPPAS, N.A. Bone tissue engineering via growth factor delivery: From scaffolds to complex matrices. Regen. Biomater. 2018, vol. 5, no. 4, pp. 197-211.

[16] SUFIIAROV, V.S. et al. Design and mechanical properties simulation of graded lattice structures for additive manufacturing endoprostheses. Mech. Adv. Mater. Struct. 2019, vol. 28, no. 16, pp. 1656-1662.

[17] PANESAR, A., ABDI, M., HICKMAN, D., ASHCROFT, I. Strategies for functionally graded lattice structures derived using topology optimisation for Additive Manufacturing. Addit. Manuf. 2018, vol. 19, pp. 81-94.

[18] KOLKEN, H.M.A. et al. Mechanical performance of auxetic meta-biomaterials. J. Mech. Behav. Biomed. Mater. 2020, vol. 104, November 2019, p. 103658.

[19] KOLKEN, H.M.A., JANBAZ, S., S., LEEFLANG, M.A., LIETAERT, K., WEINANS, H.H., ZADPOOR, A.A. Rationally designed meta-implants: A combination of auxetic and conventional meta-biomaterials. Mater. Horizons. 2018, vol. 5, no. 1, pp. 28-35. 